\title{
DEVELOPMENT OF SCHEME FOR THE ATMOSPHERIC CORRECTION OF LANDSAT-8 OLI DATA
}

\author{
V. N. Pathak ${ }^{1 *}$, M. R. Pandya ${ }^{2}$, D. B. Shah ${ }^{3}$, H. J. Trivedi ${ }^{1}$ \\ ${ }^{1}$ N.V. Patel College of Pure \& applied Sciences, Vallabh Vidyanagar-388120. (vishal31012, hjt1571)@ gmail.com \\ ${ }^{2}$ Space Applications Centre (SAC), ISRO, Ahmedabad-380015. (mrpandya@sac.isro.gov.in) \\ ${ }^{3}$ Sir P.T. Sarvajanik College of Science, Surat, Gujarat 395007. (dhirajshah123@gmail.com)
}

\section{Commission V, SS: Emerging Trends in Remote Sensing}

KEY WORD: Atmospheric Correction, Landsat-8, Surface reflectance, Aerosol, Water vapor, Ozone

\section{ABSTRACT:}

In the present study, a physics based method called Scheme for Atmospheric Correction of Landsat-8 (SACLS8) is developed for the Operational Land Imager (OLI) sensor of Landsat-8. The Second Simulation of the Satellite Signal in the Solar Spectrum Vector (6SV) radiative transfer model is used in the simulations to obtain the surface reflectance. The surface reflectance derived using the SACL8 scheme is validated with the in-situ measurements of surface reflectance carried out at the homogeneous desert site located in the Little Rann of Kutch, Gujarat, India. The results are also compared with Landsat- 8 surface reflectance standard data product over the same site. The good agreement of results with high coefficient of determination $\left(\mathrm{R}^{2}>0.94\right)$ and low root mean square error (of the order of 0.03) with in-situ measurement values as well as those obtained from the Landsat-8 surface reflectance data establishes a good performance of the SACLS8 scheme for the atmospheric correction of Landsat-8 dataset.

\section{INTRODUCTION}

Retrieval of surface reflectance from satellite data has been of prime importance as it makes possible the determination of various biophysical parameters like Albedo, Normalized Difference Vegetation Index (NDVI), Leaf Area Index (LAI), Fraction Absorbed Photosynthetically Active Radiation (fAPAR), Net Primary Productivity (NPP) etc (Liang,2004). The procedure of retrieving surface reflectance by removing path radiance due to atmosphere from the satellitemeasured radiance is called atmospheric correction. Development of physics-based atmospheric correction model that can correct the effect of atmosphere in varying aerosol, water vapor and ozone conditions is the key aspect of any atmospheric correction model. Objective of this paper is to provide a brief description on development of a new method called, SACLS8 (Scheme for Atmospheric Correction of Landsat-8) using a physics based radiative transfer (RT) model." The approach proposed here is a physics based atmospheric correction technique, which aims at producing the reflectance that would be measured at ground level. In the present work a scheme has been developed for atmospheric correction of the Landsat- 8 data. The code uses a method developed by (Pandya, 2015) to correct the remote sensing signal perturbed due to molecular and aerosol scattering (Rahman \& Dedieu, 1994 and Pandya, 2002). The scheme is based on the radiative transfer model simulations using $6 \mathrm{SV}$ code (Vermote, 2006). The model uses the raw data (digital numbers) of Landsat-8 OLI (spectral bands 1 to 7 ) along with the atmospheric parameters and viewing geometry as input to obtain the atmospherically corrected surface reflectance values. The proposed SACLS 8 model for atmospheric correction is tuned for continental aerosols and tropical atmospheric conditions. The scheme developed in the present study requires RT simulations of at-sensor reflectance and generation of coefficients using 6SV model in each spectral band of Landsat-8 OLI sensor by varying various input parameters like surface reflectance $\left(\rho_{\mathrm{s}}\right)$, sun zenith, azimuth, viewing geometry, water vapor (WV), ozone and aerosol optical thickness (AOT) (Vermote, 1997,2006). The spectral bands of Landsat-8 OLI are shown in Table-1. Continental aerosol profile and tropical atmospheric condition are used in the present study. All these calculations are carried out in particular spectral band value by convolving the relative spectral response (RSR) of Landsat-8 OLI sensor as shown in figure1.

The Landsat-8 satellite was launched on February 11, 2013 (Roy, 2014) with two sensors on board, the Operational Land Imager (OLI), which collects images in the solar spectrum and the Thermal Infrared Sensor (TIR), which collects images in the thermal infrared. These sensors are part of the series Landsat data continuity and have great importance in monitoring and mapping the Earth's surface. In this work we used the OLI sensor data. The band information for this sensor is given in Table-1.

Table1: Band information of Landsat-8 OLI data.

\begin{tabular}{cc}
\hline Band name & Spectral band \\
\hline Band1 (Coastal aerosol) & $430-450 \mathrm{~nm}$ \\
Band2 (Blue) & $450-510 \mathrm{~nm}$ \\
Band3 (Green) & $530-590 \mathrm{~nm}$ \\
Band4 (Red) & $640-670 \mathrm{~nm}$ \\
Band5 (NIR) & $850-880 \mathrm{~nm}$ \\
Band6 (SWIR1) & $1570-1650 \mathrm{~nm}$ \\
Band7 (SWIR2) & $2110-2130 \mathrm{~nm}$ \\
\hline
\end{tabular}

* Corresponding author 


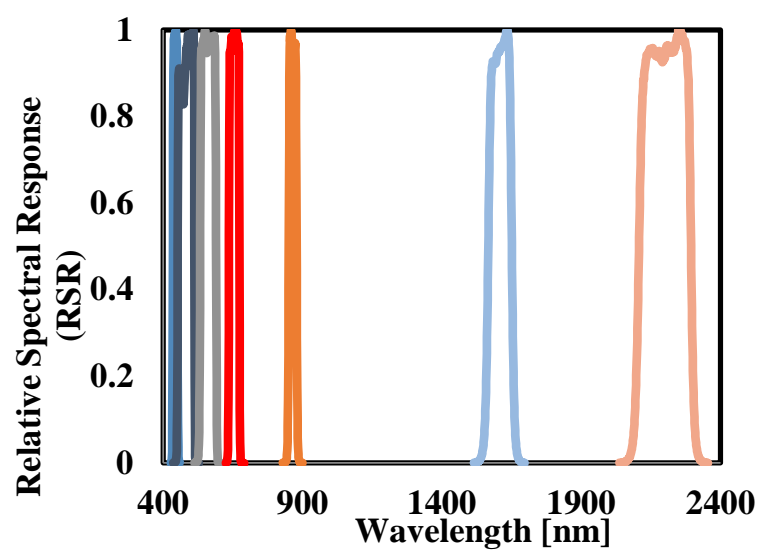

Figure1: Relative spectral responses (RSR) of Landsat-8 OLI sensors.

\section{DATA USED AND METHODOLOGY}

We have used the Landsat-8 OLI datasets (150/44) path and raw covering the region of Gujarat and surrounding on $25^{\text {th }}$ March 2014. This site provides a homogenous land cover which can serve as an excellent validation site in terms of surface reflectance (Sridhar,2013). A detailed field experiment was carried out at that time over Little Runn of Kutch in Gujarat, India on 25 ${ }^{\text {th }}$ March 2014. Microtops-II Sunphotometer measured atmospheric parameter like AOT, WV and Ozone are used in the present studies. Surface reflectance is measured using ASD Spectroradiometer (Pathak, 2014, 2016). The steps followed in the development of the model SACLS8 for the atmospheric correction of Landsat-8 OLI data are shown in Figure 2. Model derived surface reflectance values have been compared with the in-situ measurements and are compared with Landsat- 8 surface reflectance data product. In order to develop the atmospheric correction scheme for Landsat- 8 data, we have utilized the method of atmospheric correction, proposed by (Pandya, 2015) for Resourcesat-2 AWiFS data. A GUI based complete software package containing the SACLS8 model along with user guide has been developed which is shown in Figure 3 .

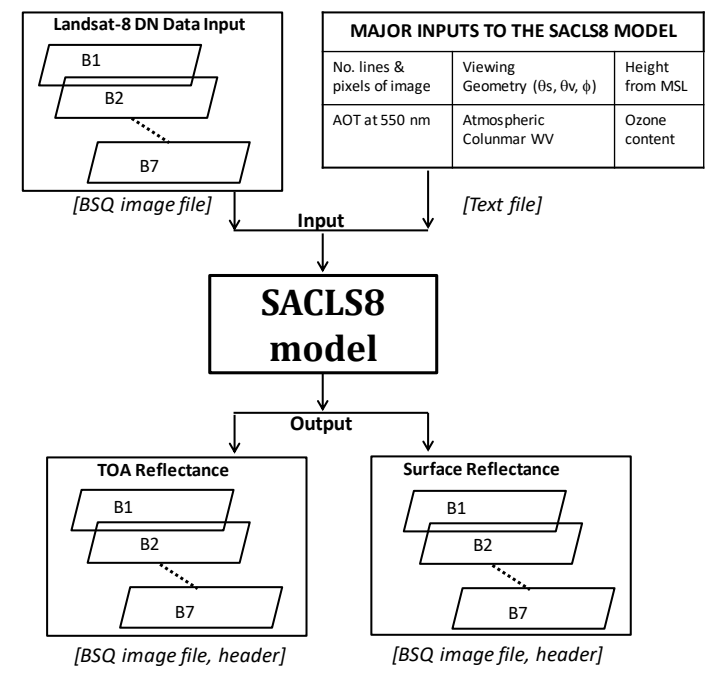

Figure 2: Schematic diagram showing the inputs and flow for the SACLS8 implementation.

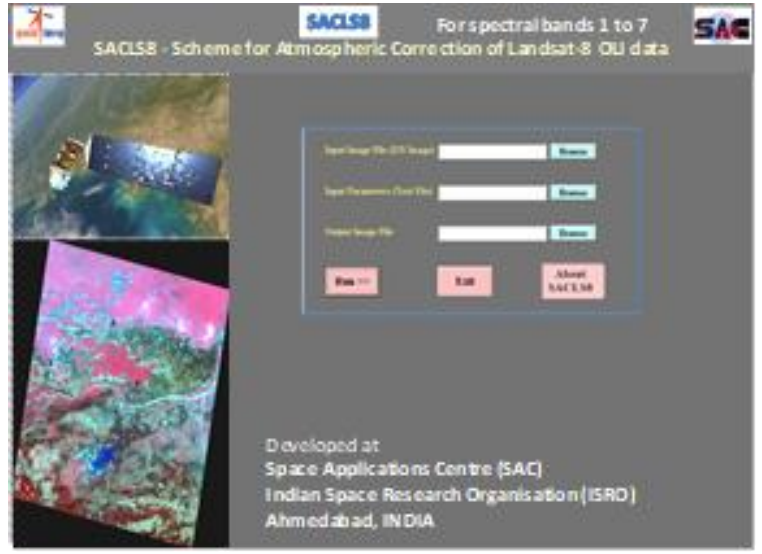

Figure 3: Snapshot of a GUI based SACLS8 model.

\section{RESULTS AND DISCUSSION}

The performance of SACLS8 model was checked by comparing the surface reflectance generated by SACLS 8 with the in-situ measurements as well as Landsat- 8 surface reflectance data product in terms of RMSE and coefficient of determination (R2). Figure 4 shows the comparison of in-situ measurements with SACLS8 derived surface reflectance and Landsat- 8 surface reflectance data product. The coefficient of determination is 0.94 to 0.96 and RMSE is around 0.03 to 0.06 when the SACLS8 generated surface reflectance is compared with in-situ measurements as shows in figures 4 and 5 .

Moreover, in order to check the performance of the SACLS8 scheme with respect to results obtained by a reference model, $6 \mathrm{SV}$ simulations were performed for the study site on the day of Landsat- 8 pass. The reflectance derived by SACLS8 scheme was compared to that of computed by the $6 \mathrm{SV}$ code. Comparison of the surface reflectance derived by various methods along with the insitu reflectance is summarized in table 2. It is evident that SACLS8 reflectance are in good agreement with that of $6 \mathrm{SV}$ reflectance.

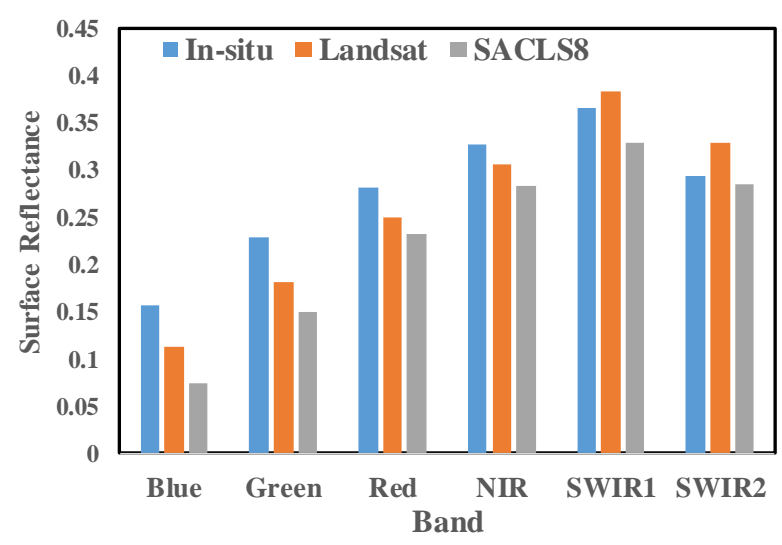

Figure 4: Comparison of Landsat-8 and SACLS8 surface reflectance with in-situ measurements 


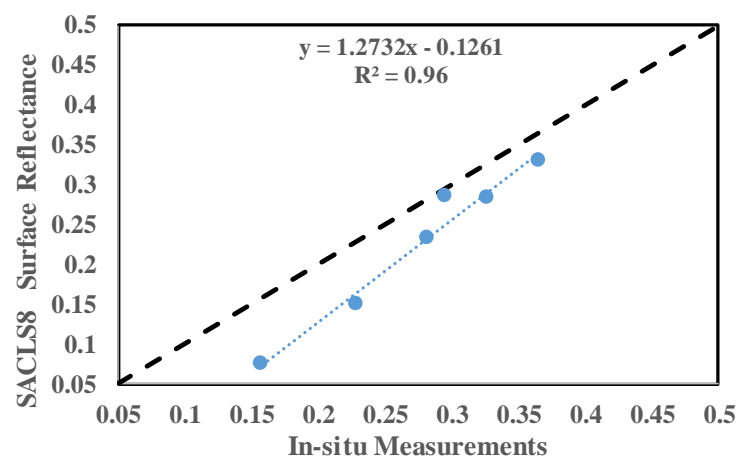

Figure 5: Comparison of Landsat-8 surface reflectance with in-situ measurements

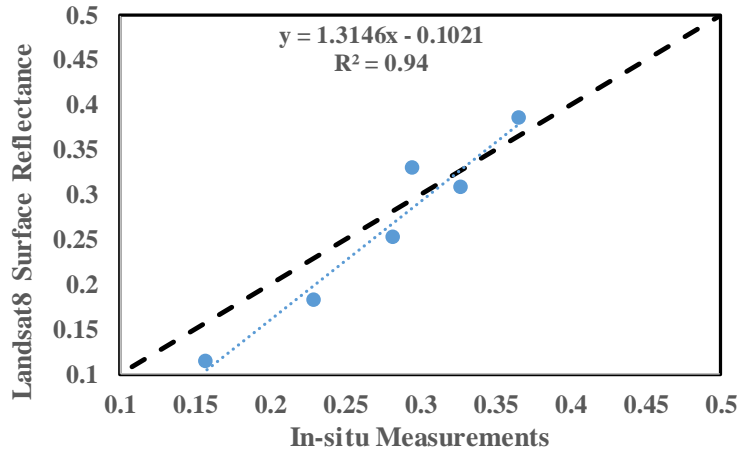

Figure 6: Comparison of SACLS8 surface reflectance with in-situ measurements

Table.2: Comparison of surface reflectance derived by different methods.

\begin{tabular}{|c|c|c|c|c|c|}
\hline Bands & TOA & $6 \mathrm{SV}$ & SACLS8 & $\begin{array}{l}\text { Landsat-8 } \\
\text { Surface } \\
\text { reflectanc } \\
\text { e product }\end{array}$ & In-situ \\
\hline Blue & 0.1388 & 0.0700 & 0.0745 & 0.1126 & 0.1574 \\
\hline Green & 0.1625 & 0.1473 & 0.1495 & 0.1816 & 0.2291 \\
\hline Red & 0.2079 & 0.2176 & 0.2320 & 0.2507 & 0.2825 \\
\hline NIR & 0.2675 & 0.2829 & 0.28 & 0.3 & 0.3272 \\
\hline SWIR1 & 0.3268 & 0.3550 & 0.3292 & & 0.3663 \\
\hline SWIR2 & 0.2555 & 0.3002 & 0.2851 & 0.3296 & 0.2949 \\
\hline
\end{tabular}

The results of the study show that the SACLS8 scheme developed in the present study, performs quite well when retrieving the surface reflectance for the OLI datasets. The GUI developed for atmospheric correction to retrieve reflectance would be useful to many researchers across the globe.

\section{CONCLUSION}

In this paper, we have seen a study that was carried out for the development of SACLS8 for the atmospheric correction of Landsat- 8 data based on 6SV RT model. This scheme corrects the Landsat- 8 data for the Rayleigh, aerosol, water vapor and ozone effects. The results of this study prove that the SACLS8 method retrieves surface reflectance value same as generate using 6SV RT model.

\section{SUMMARY AND FUTURE SCOPE}

We have developed a scheme SACLS8 for the only for continental aerosol model and tropical atmospheric profile further we do for different aerosol model and atmospheric profiles. Also in this study, we do not consider adjacency effect so in future develop atmospheric correction method for Landsat- 8 with adjacency effect.

\section{ACKNOWLEDGEMENTS}

This study has been carried out at the Space Applications Centre (SAC). Authors are grateful to Dr. V. N. Sridhar, Former Scientist, SAC for sharing the in-situ measurements and useful discussions. Authors are thankful to Ms. Radhika Chipade, Scientist, SAC for help in programing the model, Shri Shashikant Patel, Former Research Associate, SAC for his help to build a GUI based software and Dr. Basudeb Bakshi, Principal, NVPAS, Vallabh Vidyanagar for his support to the study.

\section{REFERENCES}

Liang, S., 2004. Quantitative Remote Sensing of Land Surface. Wiley Inter science, New York, 534 pp

Pandya M. R., Singh R. P., Murali K. R., Babu N., Kirankumar A. S., and Dadhwal V. K. (2002). Bandpass solar exoatmospheric irradiance and Rayleigh optical thickness of sensors on board Indian Remote Sensing Satellites-1B, 1C, 1D \& P4. IEEE Trans Geosci. Remote Sensing, 40: 714-718.

Pandya M. R., Pathak V. N., Shah D. B., Trivedi H. J. Chipade R. A., Singh R.P., Kirankumar A. S. Development of a scheme for atmospheric correction of Resourcesat-2 AWiFS data. International Journal of Applied Earth Observation and Geoinformation 40, 6573 (2015).

Pathak V. N., Pandya M. R., Shah D. B., Trivedi H. J., Patel K. D., Sridhar V. N., and Singh R. P., Inter comparison of Atmospheric Correction Models SACRS2, FLAASH and 6SV using Resourcesat-2 AWiFS Data, The International Archives of the Photogrammetry, Remote Sensing and Spatial Information Sciences, Volume XL-8, 2014

Pathak V. N., Pandya M. R., Shah D. B., Trivedi H. J. and Patel K. D., Retrieval of Surface reflectance from Resourcesat-2 AWiFS, LISS-3 and LISS-4 data using SACRS2 scheme, SPIE, 6

Pathak V. N., Development of an atmospheric correction method for retrieval of surface reflectance from satellite data, S.P.University, V.V.Nagar, Ph.D Thesis 2016.

Rahman H. and Dedieu G. (1994). SMAC: a simplified method for the atmospheric correction of satellite measurements in the solar spectrum. Int. J. Rem. Sens. 15: 123-143.

Roy D. P., Wulder M. A., Loveland T. R., Woodcock C. E., Allen R. G., Anderson M. C., Helder D., Irons J. R., Johnson D. M., Kennedy R., Scambos T. A., Shaaf C. B., Schott J. R., Sheng Y., Vermote E. F., Belward A. S., 
Bindschandler R., Cohen W. B., Gao F., Hipple J. D., Hostert P., Huntington J., Justice C. O., Kilic A., Kovalskyy V., Lee Z. P., Lymburner L., Masek J. G., Mccorkel J., Shual Y., Trezza R., Vogelmann J. Wynne R. H., Zhu Z. Landsat-8 Science and product vision for terrestrial global change research, Remote Sensing of Enviornment 145, 154-172,2014.

Sridhar V. N., Mehta K. B., Prajapati R. P., Babu K. N., Suthar N. M., and Shukla A. K. (2013). Absolute vicarious calibration of OCM2 and AWiFS sensors using a reflectance-based method over land sites in the Rann of Kutch, Gujarat. Int. J. Rem.Sens.34 (6):5690-5708.

Vermote E F, Tanŕe D, Deuzé J L, Herman M \& Morcrette J-J. (1997), Second simulation of the satellite signal in the solar spectrum, 6S: An overview. IEEE Trans. Geosci. Remote Sensing, 35: 675-686.

Vermote E., Tanré D., Deuzé J. L., Herman M., Morcrette J. J., and Kotchenova S. Y. (2006), 6S User Guide on Second Simulation of a Satellite Signal in the Solar Spectrum- Vector (6SV), Version 3, November 2006. 